\title{
Spontaneous regression of renal cell carcinoma: a pitfall in diagnosis of renal lesions
}

\author{
Y Hamid, D N Poller
}

\begin{abstract}
Two cases of renal cell carcinoma, both of which underwent extensive spontaneous regression, are reported. The first occurred in a 56 year old man, forming a well circumscribed renal cortical nodule which contained only very occasional foci of viable renal cell carcinoma with areas of hyalinisation and calcification, and with metaplastic ossification. The second lesion was removed from an 82 year old man, comprising a cystic cavity containing necrotic debris with only occasional viable foci of classical renal cell carcinoma. Spontaneous regression of renal cell carcinoma is a rare but recognised entity. These two cases emphasise the important differential diagnoses: metastatic secondary carcinomas, xanthogranulomatous pyelonephritis, and infective granulomatous conditions of the kidney. The importance of adequate tissue sampling of all renal nodules cannot be overemphasised in the processing for examination of lesions within the kidney.

(F Clin Pathol 1998;51:334-336)
\end{abstract}

Keywords: renal cell carcinoma; necrosis; regression

Hospitals NHS Trust,

Queen Alexandra

Hospital, Cosham,

Portsmouth P06 3LY,

UK

Y Hamid

D N Poller

Correspondence to:

Dr D N Poller.

Accepted for publication 20 January 1998

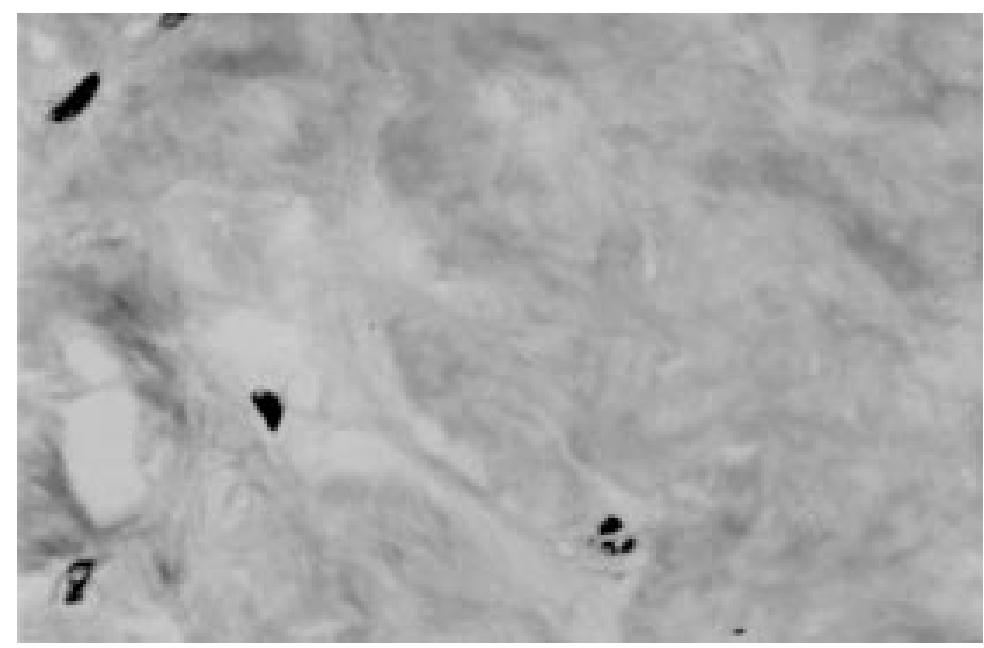

Figure 1 The majority of the tumour blocks in case 1 showed hyaline material only, without evidence of amyloid. such as haematuria or flank pain, or with an abdominal mass, or alternatively with systemic manifestations or a paraneoplastic syndrome such as anaemia, fever, symptoms of metastatic disease, and other rarer phenomena. The surgical pathology of most renal cell carcinomas is that of a moderately defined, often haemorrhagic, tumour affecting the renal cortex, commonly extending into the medulla, and with expansion of the renal capsule and extension into surrounding fat. In some instances the tumour may be multifocal. Haemorrhage, necrosis, calcification, and cystic change are common, giving a variegated appearance; nevertheless necrosis to the extent that little, if any, evidence of viable tumour remains is most unusual in surgical resection specimens unless renal vasculature has been embolised, a procedure which has fallen out of fashion. We present two cases of renal cell carcinoma showing extensive necrosis which were only diagnosed after thorough sampling of the surgical specimen, and in the first case only confirmed by immunohistochemical examination. We emphasise the importance of thorough sampling of the resected specimen, with the use of immunohistochemistry as an adjunct.

\section{Case 1}

A 56 year old man presented with left flank pain, passing calculi. A large calculus occupying the lower half of the left kidney with a right sided renal tumour was identified on computerised tomography (CT) of the upper abdomen. A right radical nephrectomy was performed. The resected surgical specimen comprised a kidney measuring $11.5 \times 6.2 \times 5.0$ $\mathrm{cm}$ with a well circumscribed cortical nodule measuring $4.1 \times 4.1 \times 3.2 \mathrm{~cm}$ present within the renal cortex and extending through the renal capsule into surrounding perinephric fat at the upper pole of the kidney. There was no evidence of tumour within the renal medulla or calyces, and the kidney elsewhere appeared unremarkable. The total kidney with associated perinephric coverings weighed 273 g. Microscopically the tumour was an extensively involuted/hyalinised lesion (fig 1) with extensive metaplastic ossification and also foci of dystrophic calcification. However, within the foci of hyalinisation were occasional foci of cells with clear cytoplasm and ovoid or slightly rounded nuclei (fig 2), which showed positive immunostaining with low molecular weight cytokeratin (Cam 5.2)(fig 3) and epithelial membrane antigen (EMA). The appearances were undoubtedly those of an extensive involuted renal cell carcinoma. Local excision 


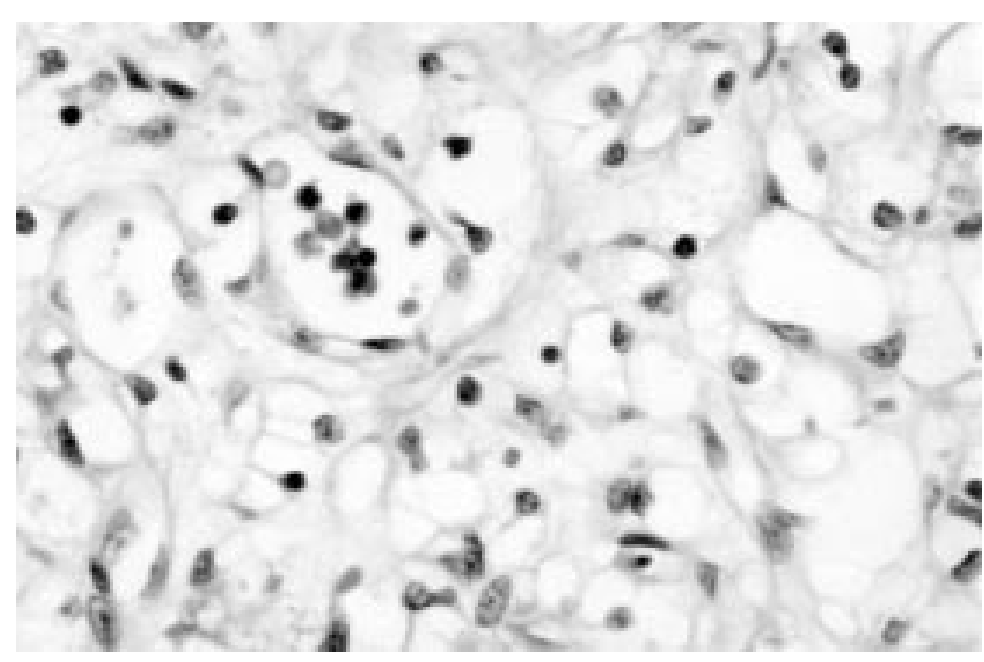

Figure 2 Occasional foci of viable malignant cells with clear cytoplasm identified within area of hyaline change.

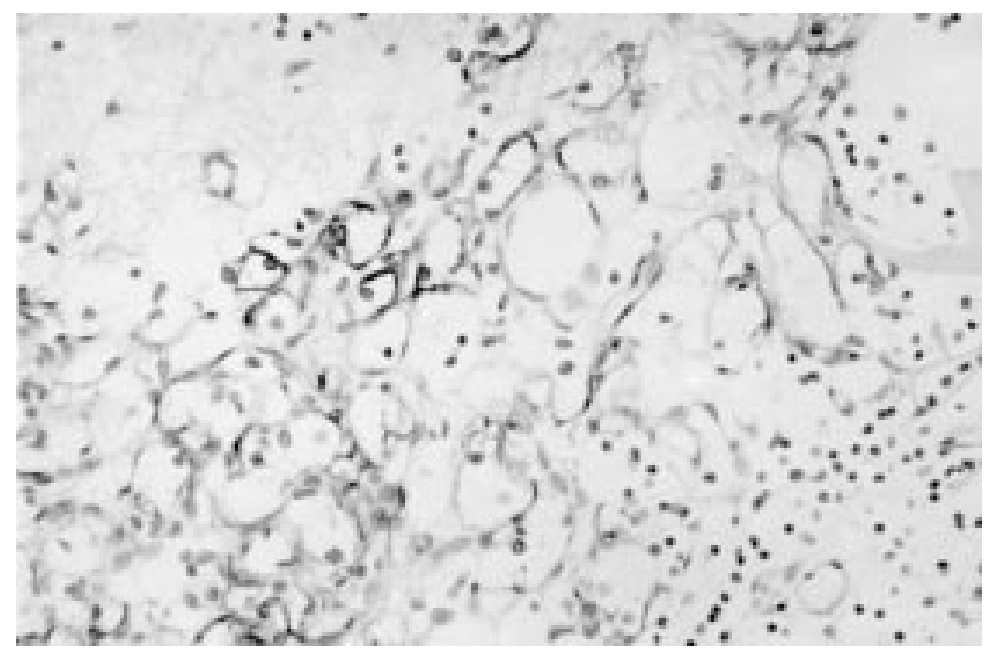

Figure 3 The epithelial rather than vascular endothelial nature of these cells is confirmed by positive immunostaining with low molecular weight cytokeratin Cam5.2 (shown above) and EMA (not shown). complete at the fascial excision planes. Again multiple blocks were required to identify that this was indeed a renal cell carcinoma

\section{Discussion}

Spontaneous involution of renal cell carcinoma is described, ${ }^{4}$ although most published reports refer to regression of metastatic lesions following resection of a primary renal cell carcinoma, ${ }^{56}$ particularly after cytokine treatment ${ }^{7}$ rather than regression of primary renal cell carcinomas. The identification of viable tumour in extensively necrotic lesions may cause diagnostic difficulty and it is accepted that multicystic lesions containing small populations of clear cells may require extensive sampling to confirm the presence of a very small population of malignant cells, indicating renal cell carcinoma. ${ }^{8}$ Immunohistochemistry is often very useful in this situation, as it can positively confirm the epithelial nature of cells which are morphologically suspicious. Renal cell carcinomas typically express keratins, epithelial mucin antibody (EMA), carcinoembryonic antigen (CEA), and vimentin, often with coexpression of keratin and vimentin. ${ }^{9}$ Expression of other antigens, for example villin, $\quad \alpha 1$-antitrypsin, $\alpha 1-$ chymotrypsin, S100 protein, Lewis blood group antigens, angiotensin converting enzyme, parathormone related protein, and prealbumin is also described, as well as other miscellaneous antigens. ${ }^{9}$ Monoclonal antibodies have also been generated against epitopes present in renal cell carcinoma, some poorly characterised or uncharacterised, suggesting that most renal cell carcinomas show proximal tubular differentiation. ${ }^{9}$ Cells suspicious of tumour within necrotic cystic renal lesions may also arise as a result of macrophage-like cells in benign inflammatory lesions of the kidney, such as xanthogranulomatous pyelonephritis. ${ }^{10}$ These cells characteristically stain with macrophage/histiocytic markers such as MAC387 and CD68, failing to stain with keratins, EMA, CEA, or vimentin. The differential diagnosis of spontaneously regressed renal cell carcinoma would also include:

- previous tumour embolisation, which may have been performed without the surgical pathologist's knowledge (although this procedure has fallen out of fashion in urological practice)

- malacoplakia, in which typical MichaelisGuttman bodies should be readily identifiable on D-PAS or Von Kossa stains and confirmed as bacterial-like bodies on electron microscopy

- xanthogranulomatous reaction to the presence of a staghorn calculus

- tuberculosis and other infective granulomatous conditions of the kidney

- sinus histiocytosis with massive lymphadenopathy (Rosai-Dorfman disease).

Regressed renal cell carcinoma is an important differential diagnosis of solitary renal lesions. Only thorough tumour sampling of the pathological specimen, or in the case of CT guided core or fine needle aspiration (FNA) 
biopsy, previous knowledge of the ultrasound, $\mathrm{CT}$, or magnetic resonance imaging findings will ensure that the correct diagnosis is made, or in the case of a non-diagnostic core biopsy or FNA, that further appropriate clinical action is taken.

1 Malek RS, Omess PJ, Benson RC, et al. Renal cell carcinoma in von Hippel-Lindau syndrome. Am $\mathcal{F}$ Med 1987;82:2368 .

2 Gregoire JR, Torres VE, Holley KE, et al. Renal epithelial hyperplastic and neoplastic proliferations in autosomal
dominant polycystic kidney disease. Am F Kidney Dis 1987; 9: $27-38$.

3 Bernstein J, Evan AP, Gardner KD. Epithelial hyperplasia in human polycystic kidney diseases. Its role in pathogenesis and risk of neoplasia. Am f Pathol 1987;129:92-101.
4 Millan JC. Tumors of the kidney. In: Hill G S, ed. Uropathology, vol 2. Edinburgh: Churchill Livingstone, 1989:623-701.

5 Deweerd JH, Hawthorne NJ, Adson MA. Regression of renal cell hepatic metastasis following removal of primary lesions. F Urol 1977;117:790-2.

6 Bos SD, Mensink HJ. Spontaneous caval tumor thrombus necrosis and regression of pulmonary lesions in renal cell cancer. Scand $\mathcal{F}$ Urol Nephrol 1996;30:489-92.

7 Marcus SG, Choyke PL, Reiter R, et al. Regression of metastatic renal cell carcinoma after cytoreductive nephrectomy. F Urol 1993;150:463-6.

8 Murad T, Komaiko W, Oyasu R, et al. Multilocular renal cell carcinoma. Am f Clin Pathol 1991;95:633-7.

9 Ordonez NG, Rosai J. Urinary tract. In: Hill GS, ed. Ackerman's surgical pathology, 8th ed, vol 1. London: C V Mosby, 1996:1059-220.

10 Goodman M, Curry T, Russell T. Xanthogranulomatous pyelonephritis (XGP). A local disease with systemic maniliterature. Medicine (Baltimore) 1979;58:171-81. 